Editorial

\title{
Preservation of Cultural Heritage and Resources Threatened by Climate Change
}

\section{Chiara Bertolin $\mathbb{D}$}

Department of Architecture and Technology, Norwegian University of Science and Technology, Alfred Getz vei 3, 7491 Trondheim, Norway; chiara.bertolin@ntnu.no

Received: 24 May 2019; Accepted: 27 May 2019; Published: 3 June 2019

\begin{abstract}
With a wide spectrum of data, case studies, monitoring, and experimental and numerical simulation techniques, the multidisciplinary approach of material, environmental, and computer science applied to the conservation of cultural heritage offers several opportunities for the heritage science and conservation community to map and monitor the state of the art of the knowledge referring to natural and human-induced climate change impacts on cultural heritage-mainly constituted by the built environment-in Europe and Latin America. The special issue "Preservation of Cultural Heritage and Resources Threatened by Climate Change" of Geosciences-launched to take stock of the existing but still fragmentary knowledge on this challenge, and to enable the community to respond to the implementation of the Paris agreement-includes 10 research articles. These papers exploit a broad range of data derived from preventive conservation monitoring conducted indoors in museums, churches, historical buildings, or outdoors in archeological sites and city centers. Case studies presented in the papers focus on a well-assorted sample of decay phenomena occurring on heritage materials-e.g., surface recession and biomass accumulation on limestone, depositions of pollutant on marble, salt weathering on inorganic building materials, and weathering processes on mortars in many local- to regional-scale study areas in the Scandinavian Peninsula, the United Kingdom, Belgium, France, Italy, Greece, and Panama. Besides monitoring, the methodological approaches that are showcased include, but are not limited to, original material characterization, decay product characterization, and climate and numerical modelling on material components for assessing environmental impact and climate change effects.
\end{abstract}

Keywords: cultural heritage; climate change; decay; preventive conservation; mitigation actions; heritage materials; indoor climate; outdoor climate

\section{Introduction}

Changes in preservation conditions due to climate-related decay processes are unavoidable phenomena for both movable and immovable cultural heritage $(\mathrm{CH})$. The knowledge of the mechanisms governing these processes and their real effect on changing heritage significance will allow the rational use of heritage materials, as well as the anticipation of their behavior beforehand, in order to succeed in preventive conservation, heritage management, and eventual restoration.

The degradation progress, which depends on external agents of decay, exposure, the intrinsic properties of the material to be studied, and object construction vulnerability, is nowadays exacerbated by both anthropic factors and the impact of climate change (CC).

Due to more frequent and severe weather events, greater exposure, ageing of materials, and the existence of previous conservative interventions, the need for adapting cultural heritage to anthropic and climate change-related effects is becoming more and more urgent. Within cultural heritage, the risk from climate change is more pronounced for the built environment, where the right adaptation interventions should be chosen properly considering the buildings' capacity to change due to its 
protection status under the law, the principle of preservation, and the need to apply effective mitigation actions. The International Council on Monuments and Sites (ICOMOS) principles of preservation [1] ask to

- understand and respect $\mathrm{CH}$ and its significance;

- $\quad$ be cautious in designing interventions;

- $\quad$ respect authenticity and integrity;

- propose reversible interventions to-as much as possible-keep intact existing original materials;

- $\quad$ prioritize preventive and effective care;

- $\quad$ prioritize minimum intervention: "do as much as necessary and as little as possible";

- $\quad$ propose compatible design solutions, i.e., use adequate materials, techniques, and detailing with regard to material and physical-chemical-mechanical interactions between the new and the existing;

- $\quad$ enhance the use of cultural assets and regularly programmed maintenance necessary to extend the service life of the $\mathrm{CH}$;

- enhance multi-disciplinary action-i.e., call upon skill and experience from a range of relevant disciplines.

For movable objects (often preserved indoors in museums or historical buildings), climate change-induced risks manifest themselves in greater difficulty of management, due to higher costs for cooling/heating demand related to maintaining appropriate environmental conditions, as requested by the American Society of Heating, Refrigerating and Air-Conditioning Engineers (ASHRAE) and the European Committee for Standardization (CEN) standards, as well as higher costs for conducting preventive conservation due to the new appearance or acceleration of decay phenomena.

The Council of Europe's European Heritage Strategy for the 21st Century [2] calls for more reliable quantified information on the impact of climate change on cultural heritage, as the changing climate, speeding up the rate of degradation and the risk of loss of value, is affecting the organizations who take care of cultural heritage, resulting in difficulties in managing the maintenance of heritage buildings outdoors and the indoor environments caused by increasing costs and lack of funds. As a whole, this in turn affects the cultural tourism sector, local and regional economies, their traditional practices in maintenance and conservation, as well as their use of resources and adaptation planning options.

However, limited research has been accomplished to date on the process of preserving $\mathrm{CH}$ threatened by CC, as very few tools or methods exist to collect and analyze data on the actual situation, and at the same time estimate the ongoing and expected risks.

The main objectives of this special issue are

- $\quad$ to make the point about the ongoing research in the field;

- $\quad$ to present new data, methods, and techniques that can be used by a wide community of researchers and conservators to better understand degradation phenomena affecting heritage materials, and to assess the actual and expected impact of CC;

- to provide guidance on conservation principles and standards to follow in order to enhance awareness on preventive conservation and long-term planned conservative interventions in the time of CC;

- $\quad$ to develop mitigation and adaptation capacity throughout the wide range of stakeholders involved, as it is urgent to respond to CC now.

\section{Overview of the Special Issue Contributions}

The special issue (SI) of Geosciences titled "Preservation of Cultural Heritage and Resources Threatened by Climate Change" has been launched to take stock of the existing, but still fragmentary knowledge on this challenge, and to enable the heritage community to respond to the implementation of the Paris Climate agreement. At the European level, only two projects, "Noah's Ark" [3] and 
"Climate for Culture" [4], have finalized their research on these issues. The SI encompass 10 open access papers presenting research studies based on the exploitation of a broad range of data deriving from preventive conservation monitoring [5-7] and climate or numerical modelling on material components for assessing environmental impact and climate change effects [8,9]. These papers are focused on a well-assorted sample of decay phenomena occurring on heritage materials, e.g., surface recession and biomass accumulation on limestone [10], depositions of pollutant on marble [11], salt weathering on inorganic building materials [12], and the weathering process on mortars [13]. Finally, one paper [14] is devoted to examining the perceptions of experts involved in the management of cultural heritage on adaptation to climate change risks.

Table 1 summarizes the distribution of data and techniques used in each paper, the target decay type monitored or simulated on one or more heritage materials, and the considered climate change scenario and assessment time.

Table 1. Overview of data, techniques, target decay, heritage material, and climate change scenario, with the assessment times presented in the 10 open access research papers composing the special issue (SI) "Preservation of Cultural Heritage and Resources Threatened by Climate Change" of Geosciences. The papers are in order of publication.

\begin{tabular}{|c|c|c|c|}
\hline Paper Reference and DOI & $\begin{array}{l}\text { Data and Processing/Analyzing } \\
\text { Method }\end{array}$ & Type of Decay and CH Material & $\begin{array}{c}\text { CC Scenario and Assessment } \\
\text { Time }\end{array}$ \\
\hline $\begin{array}{c}\text { Anaf et al. [5] } \\
\text { doi:10.3390/geosciences8080276 }\end{array}$ & $\begin{array}{l}\text { Monitoring data; Indoor Air } \\
\text { Quality (IAQ) index for heritage } \\
\text { application }\end{array}$ & $\begin{array}{l}\text { Overall IAQ risk; air-mixed } \\
\text { materials/objects }\end{array}$ & $\begin{array}{l}\text { Real time or post-adaptation } \\
\text { measures assessment }\end{array}$ \\
\hline $\begin{array}{c}\text { Ciantelli et al. [10] } \\
\text { doi:10.3390/geosciences8080296 }\end{array}$ & $\begin{array}{c}\text { Meteo-climate data (Temperature, } \\
\text { Relative Humidity, rain) and main } \\
\text { construction materials } \\
\text { characterization }\end{array}$ & $\begin{array}{l}\text { Pollution and salt crystallization } \\
\text { cycles; masonries }\end{array}$ & $\begin{array}{l}\text { Reference period: } 1979-2008 \text { and } \\
\text { future: 2039-2068; EC: Earth } \\
\text { global climate model with high } \\
\text { GreenHouse Gas (GHG) emissions }\end{array}$ \\
\hline $\begin{array}{c}\text { Sesana et al. [14] } \\
\text { doi:10.3390/geosciences8080305 }\end{array}$ & $\begin{array}{l}\text { Stakeholder interviews and } \\
\text { participatory workshop; best } \\
\text { practices in adaptation }\end{array}$ & $\begin{array}{l}\text { Hazards exacerbated by CC (flood, } \\
\text { landslides, Sea Level Rise) }\end{array}$ & $\begin{array}{c}\text { Reanalysis of past experience for } \\
\text { future strategic planning and } \\
\text { preparedness }\end{array}$ \\
\hline $\begin{array}{c}\text { Carroll and Aarrevaara [6] } \\
\text { doi:10.3390/geosciences8090322 }\end{array}$ & $\begin{array}{l}\text { Materials and structures } \\
\text { classification; urgency index }\end{array}$ & $\begin{array}{l}\mathrm{T} \text { and precipitation trends } \\
\text { resulting from CC; Mixed } \\
\text { materials on buildings }\end{array}$ & $\begin{array}{l}\text { Climate trends and assessment of } \\
\text { past adaptation measures }\end{array}$ \\
\hline $\begin{array}{c}\text { Dotsika et al. [13] } \\
\text { doi:10.3390/geosciences8090339 }\end{array}$ & $\begin{array}{c}\text { Isotopic data from mortar samples } \\
\text { collected at different depths; stable } \\
\text { isotope analysis }\end{array}$ & $\begin{array}{l}\text { Chemical decay due to pollution } \\
\text { and environmental conditions, } \\
\text { and the secondary decay } \\
\text { mechanism of carbonate } \\
\text { formation from salt weathering } \\
\text { and biological attack; mortars }\end{array}$ & $\begin{array}{c}\text { Analysis of weathering } \\
\text { progression from Hellenistic, Late } \\
\text { Roman, and Byzantine mortar } \\
\text { layers }\end{array}$ \\
\hline $\begin{array}{c}\text { Loli and Bertolin [8] } \\
\text { doi:10.3390/geosciences } 8090347\end{array}$ & $\begin{array}{l}\text { Climate for culture maps and } \\
\text { building protection levels by law; } \\
\text { decay level estimation and } \\
\text { allowable interventions }\end{array}$ & $\begin{array}{l}\text { Chemical, biological, mechanical; } \\
\text { mixed buildings materials }\end{array}$ & $\begin{array}{l}\text { Far future: } 2071-2100 ; \\
\text { Regional Model, rapid economic } \\
\text { growth (A1B) and representative } \\
\text { concentration pathway to } 4.5 \\
\text { W/m }{ }^{2} \text { radiative forcing value } \\
\text { within } 2100 \text { (RCP4.5) scenarios }\end{array}$ \\
\hline $\begin{array}{c}\text { Fermo et al. [11] } \\
\text { doi:10.3390/geosciences8090349 }\end{array}$ & $\begin{array}{l}\text { Monitored data on deposited } \\
\text { aerosol particulate matter (PM) on } \\
\text { quartz filters and main ions, } \\
\text { atmospheric pollution data; } \\
\text { chemical characterization }\end{array}$ & $\begin{array}{l}\text { Environmental deposition; marble } \\
\text { and surrogate substrates }\end{array}$ & Present: 2014-2017 \\
\hline $\begin{array}{c}\text { Haugen et al. [7] } \\
\text { doi:10.3390/geosciences } 8100370\end{array}$ & $\begin{array}{l}\text { Environmental monitoring (T, RH) } \\
\text { and moisture content on wood; } \\
\text { zero-level registration and } \\
\text { interval-based registration system } \\
\quad \text { for relevant indicators }\end{array}$ & $\begin{array}{l}\text { Mixed decays on stone and } \\
\text { wooden historical buildings }\end{array}$ & $\begin{array}{l}\text { Present-day monitoring is planned } \\
\text { to continue for } 30-50 \text { years }\end{array}$ \\
\hline $\begin{array}{c}\text { Bylund Melin et al. [9] } \\
\text { doi:10.3390/geosciences8100378 }\end{array}$ & $\begin{array}{l}\text { Monitoring of } \mathrm{T} \text { and } \mathrm{RH} \text { to } \\
\text { simulate moisture content in } \\
\text { wood; monitoring, experimental } \\
\text { tests, and simulations using WUFI } \\
\text { Pro software and simplified } \\
\text { mathematical models }\end{array}$ & $\begin{array}{l}\text { Moisture diffusion and transport } \\
\text { that can induce primary } \\
\text { mechanical decay and secondary } \\
\text { effects; wood or hygroscopic } \\
\text { materials }\end{array}$ & $\begin{array}{l}\text { Building simulations and climate } \\
\text { change scenarios }\end{array}$ \\
\hline $\begin{array}{c}\text { Menéndez [12] } \\
\text { doi:10.3390/geosciences8110401 }\end{array}$ & $\begin{array}{l}\text { Phase change phenomena of } \\
\text { common salts; comparison of } \\
\text { predicted changes in weathering } \\
\text { driven by single or mixed salts. }\end{array}$ & $\begin{array}{l}\text { Salt weathering; historical } \\
\text { buildings }\end{array}$ & $\begin{array}{c}\text { Present and future simulation of } \\
\text { weathering }\end{array}$ \\
\hline
\end{tabular}




\section{Data, Methods, and Decay on Cultural Heritage Material under Climate Change Scenarios}

In their paper, Anaf et al. [5] present a new tool to help heritage guardians in processing and evaluating monitored data in museums or heritage buildings. The work explains the backbone of their proposed Indoor Air Quality (IAQ)-calculating algorithm, from the recognition of deterioration agents, to conversion functions for calculating the level of risk in specific materials or objects, to the way in which weight is attributed to key risk indicators (KRIs). The combination of all KRIs constitutes the overall IAQ index. The authors clearly present this new tool, visually processing sets of multi-monitored data applied to canvas painting, restrained wood, and copper preserved in a church in Belgium. This allows the identification and discussion in detail of the potential and limitations of the IAQ index for assessing the effectiveness of mitigation actions implemented by a heritage institution. Finally, this tool helps to better manage the indoor environment, in order to adapt it to a changing climate.

Keeping the focus on data assessment derived from environmental monitoring in museums as heritage institutions, Carroll and Aarrevaara [6] reanalyze literature findings about the range of local weather- and climate-related factors that contribute to the degradation of cultural heritage buildings and structures over time. These factors manifest themselves by speeding up the rate of degradation. The authors propose a method to collect information about where best to concentrate cultural heritage site preservation resources in the future, based on an urgency rate index. This proposed numerical scale index ranging from 1 to 10 can be applied to several CC categories (i.e., warmer climate, longer growing season, increased precipitation, severe rain, and extreme winds), to be evaluated both in terms of the rate of change (i.e., the increase in ${ }^{\circ} \mathrm{C} / \mathrm{yr}$, days $/ \mathrm{yr}, \mathrm{mm} / \mathrm{yr}, \mathrm{mm} / \mathrm{hr}$, or $\mathrm{m} / \mathrm{s}$, respectively) and a visual inspection on the affected structures or materials. Arctic regions are predicted to face the greatest increase of warming in winter time. The temperature is expected to rise by $3-4{ }^{\circ} \mathrm{C}$ by 2050 . Rainfall in Nordic countries will increase by about $10 \%$ on an annual level. Exceptionally, the west coasts of Norway and Finland might face as much as a $20-30 \%$ increase in rainfall in winter periods. This will turn to cause favorable conditions for fungal growth and pest damage. To highlight such risks, and to show the potentiality of the proposed model, Carroll and Aarrevaara apply it to evaluate the outdoor conditions of a Finnish farmhouse complex consisting of several buildings in Finland. The method, as well as the discussion of its results, serves the purpose of prioritizing cultural heritage materials and elements for protection against the ravages of climate change, therefore helping conservators and heritage managers in planning for adaptation or mitigation steps.

From the majority of the works presented in the SI, it is clear that a long-term strategy to adapt to climate change must be based on risk assessment, adaptation measures, and monitoring. Specifically, due to the still-high degree of uncertainty in simulations, long-term monitoring of the actual impact of climate change is necessary to better understand the effects of climate change on historic buildings. Monitoring can be used to observe and analyze decay progress, as already stated in [5,6], in order to provide reference data to improve the results of simulation models; inform decisions on adaptative or corrective actions; raise awareness among property owners, heritage managers, and citizens; and to gain political and economic support locally, regionally, and nationally. Looking at systematic, well-planned, long-term management, Haugen et al. [7] presents an innovative methodological approach that is able to record climate change-induced decay on historic buildings and interiors at the national scale. The additional challenge here is the long time frame needed to discern the climate change signal from the natural variability of the climate. This time frame ( $>30$ years) exceeds the scope of most research funding schemes, and there are also practical difficulties in maintaining such long projects with regard to administration, staff continuity, data retrieval and storage, etc.

In the first part of their paper, Haugen et al. [7] present the generic framework of the novel methodology. This framework is based on a review of existing approaches to climate change monitoring of cultural heritage, as well as the experiences from the Norwegian pilot project known as "Methods for Monitoring the Effects and Consequences of Climate-Related Degradation of Buildings", which proposes, for the first time, zero-level registration and an interval-based registration system focused 
on relevant decay indicators to detect the effects of climate-induced degradation. The second part of the paper presents, as a case study, the implementation of a newly started, long-term monitoring campaign on 45 medieval buildings distributed over the entirety of Norway. Thirty-five of these buildings are dated to before 1537, and include wooden buildings as well as 10 medieval churches built in stone, while the remaining 10 buildings are situated in the World Heritage sites of Bryggen in Bergen, on the west coast of Norway, and in Røros. Last but not least, the importance of the early involvement of researchers and stakeholders (e.g., the directorate of cultural heritage, conservators, heritage institutions, staff and building owners, etc.) from an early stage is fundamental for the success of such a long-term monitoring program.

Moving from research studies based on the exploration of data from preventive conservation monitoring to climate and numerical modelling on material components for assessing climate change effects, Loli and Bertolin [8] present multi-risk scenarios of CC on building materials, using data from the European Union (EU)-funded project Climate for Culture (CfC) [4]. The authors employ a modified version of the risk assessment method developed in the $\mathrm{CfC}$ project to take into consideration the proper adaptation intervention to be applied on historic buildings. The authors link the majority of climate-induced decay variables, describing mechanical, chemical, and biological decay on several building materials (e.g., masonry, concrete, and wood) and structures, with the buildings' capacity to change due to their protection status. The merging of the decay results with the building protection level becomes an indicator of the right level and time for intervention for climate change adaptation. The proposed method was then tested on 38 locations in Scandinavian countries to estimate the influence of climate change on future interventions on historic buildings [8].

A risk assessment matrix of deterioration highlights that, over the far future (i.e., 2071-2100), the risk of chemical and biological decays (outdoors) will slightly increase, especially in the southern part of the Scandinavian peninsula, while the mechanical decay of building materials kept indoors will generally decrease. This, for example, will require high-priority interventions for small, heavyweight buildings located in the area near Göteborg and Malmö, in order to adapt measures that minimize the climate-induced decay expected over the far future.

With a similar approach to the use of climate, building, and material modelling, Bylund Melin et al. [9] propose a study to increase the knowledge of climate-induced damage to heritage objects, which is essential to monitor moisture transport in wood. In fact, hygroscopic materials, such as wood, will gain and release moisture during changes in relative humidity $(\mathrm{RH})$ and temperature $(\mathrm{T})$. These changes cause swelling and shrinkage, which may result in permanent damage. To propose simulation models that are able to predict how the influence of climate change will modify the wood moisture content, and consequently the risk of shrinkage and swelling, is of primary importance. Bylund Melin et al.'s approach is completely multi-disciplinary, as they compare experimental data acquired in the laboratory, such as monitored temperature $(\mathrm{T})$ and relative humidity $(\mathrm{RH})$ at different depths inside wooden samples subjected to fluctuating climate over time, with novel methods, i.e., the use of hygrothermal building simulation software WUFI Pro to simulate object components, as well as a simplified model to calculate the moisture content. The conclusion was that both methods can simulate moisture diffusion and transport in wooden object with sufficient accuracy. In addition, both methods for predicting climate change data show that the mean RH inside wood remains rather constant, but the RH minimum and maximum vary with the predicted scenario and the type of building used for the simulation.

With a specific look at surface recession and biomass accumulation on limestone as a long-term climate change effect, Ciantelli et al. [10] present a case study in Latin America, in Panamá Viejo (a $16^{\text {th }}$-century building) and at the Fortresses in Portobelo and San Lorenzo (17th- to 18th-centuries). The authors first analyzed the main construction materials at the site level (i.e., masonries and limestone), adopting several investigation techniques (e.g., stereomicroscope, polarized light microscopy, X-ray powder diffraction, environmental scanning electron microscopy, ion chromatography), and then they analyzed changes in rainfall, $\mathrm{RH}$, and surface air $\mathrm{T}$ as key drivers of the deterioration of cultural 
heritage. They applied future model predictions (running EC-Earth Global Earth System Model at high horizontal resolution) of these variables in damage functions to study the different kinds of material decays that might occur in the future. In particular, all functions they considered indicate an increase in surface recession, biomass accumulation, and cycles of dissolution and crystallization of halite in the future (2039-2068) with respect the past (1979-2008), especially in the North Coast, as shown by the analysis performed at the San Lorenzo and Portobelo areas. Nevertheless, the Panamá Viejo zone also shows an increment of surface recession and biomass accumulation; while considering the salt cycles, growth is projected to decrease. This work represents an important contribution to better understanding the possible future impact of CC on the heritage sites of Central America, and to support their management, restoration, and preservation.

With similar objectives Fermo et al. [11] present the results of the field exposure activity conducted between 2014 and 2017 on the marble façade of the cathedral in Milan, Italy. The authors performed a complete chemical characterization in real exposure conditions, quantifying deposited aerosol particulate matter (PM) and main ions on quartz filters and marble substrates. Through their monitoring strategy, they were able to discriminate between the compositions of the deposits, mainly depending on the type of substrate used (e.g., stone-Candoglia marble-substrates and quartz fibre filters as surrogate substrates), exposed on two sites of the cathedral façade at different heights. On the quartz filters, the carbonaceous component of the deposits was also investigated, as well as the color change induced by soiling, by means of colorimetric measurements.

The paper by Dotsika et al. [13] analyze 63 samples of mortars collected from lime and hydraulic mortars affected by environmental degradation, obtained from Hellenistic, Late Roman, and Byzantine historic constructions located at Kavala, Drama, and Makrygialos in northern Greece. The analysis of isotopic data allowed the re-creation of an ideal Hellenistic and Byzantine mortar layer to study weathering gradients. In fact, authors collected the first sample from the external layer, while the internal samples each were from $1 \mathrm{~cm}$ deeper than the previous, in order to monitor the moisture ingress. The obtained results indicate that a stable isotope analysis is an excellent tool to fingerprint the origin of carbonate, the environmental setting conditions of mortar, and the origin of $\mathrm{CO}_{2}$ and water during calcite formation, as well as to determine the weathering depth and potential secondary degradation mechanisms, such as the recrystallization of calcite with pore water and salt attack.

Correspondingly, with a combination of methods described in $[10,11,13]$, i.e., material analysis, damage function application, and climate change scenarios, Menéndez [12] estimates the salt weathering induced by climate change on built cultural heritage in 41 locations in France. In the analysis of phase-change phenomena, the author uses not only the two most common salts held responsible for decay, i.e., sodium chloride and sodium sulfate, but also others like calcium sulfate or mixtures of chlorides, sulfates, and nitrates of sodium, calcium, magnesium, and potassium. The novelty of this work is that it proposes a comparison between the predicted changes in salt weathering obtained from the presence of a single salt and a combination of different salts. The results achieved by Menéndez demonstrate how estimations of actual and future weathering depend on the selected salts. In addition, when using a combination of different salts, the weathering evolution is less favorable than when using a single salt.

Last but not least, Sesana et al. [14] examine, using semi-structured interviews, the perceptions of experts involved in the management of cultural heritage with regard to adaptation to climate change risks. This is a very sensitive topic, due to greater exposure to severe weather events; however, to date, limited research has been accomplished in the literature on the process of adaptation. In the paper, the authors report answers obtained by the contacted experts in the United Kingdom, Italy, and Norway, resulting from a participatory workshop organized with stakeholders on management methodologies that contemplate climate change impacts and examples of best practice. The work dispenses insights on opportunities and barriers in adaptation, including requirements for preparedness and future strategic plans for cultural heritage protection in the time of climate change. 


\section{Statistics, Bibliometrics, and Impact}

The 10 research papers were published in the special issue between the end of July 2018 and early November 2018, with an average time of less than two months from first submission to online publication. Each manuscript was assessed via rigorous peer reviewing from two or more esteemed experts in the respective field.

The geographic distribution of the authors and research teams publishing in the SI and of the case studies are reported in Figure 1.

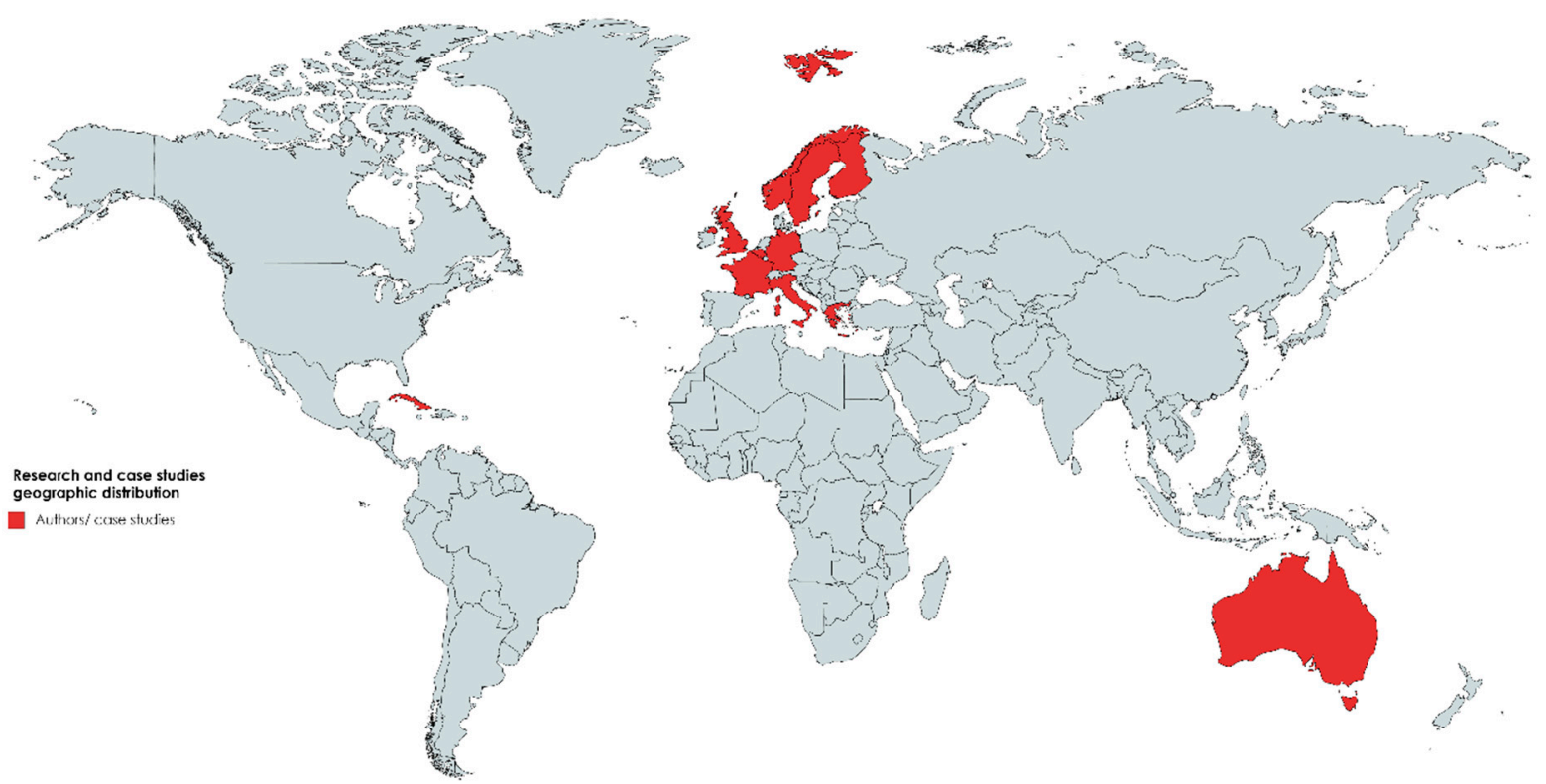

Figure 1. Geographic distribution of authors and research teams publishing in the special issue. Case studies are located in the same countries belonging to the authors, except for Australia, Cuba, and Germany, while a case study not highlighted in the map is located in Panama.

This is, of course, a sample of the whole scientific community working on climate change impacts on cultural heritage, although not an exhaustive representation. However, it already provides a glimpse of the widespread expertise of experimental research, field practice, building, and climate simulation, and proves how widely the conservation of cultural heritage is applied to investigate, mitigate, and adapt to the impacts of climate change.

Based on article metrics powered by PlumX on Scopus, overall, the published papers have already received eight citations in the indexed literature in the first few months after publication, with an average of almost one citation per paper, proving the immediate impact of the published research. Additionally, the item-level metrics provide insights into the ways people interact with the articles constituting the SI in the online environment. Beside the main scientific outcome of the citation metric, the other stronger interactions are in captures and social media areas, with an average of six captures as bookmarks, favorites, and reference manager saves by readers, and an average of six tweets, likes, and shares on social media. This could indicate that the SI papers are already being consumed and talked about.

Figure 2 highlights the disciplines and scientific domains on which the 35 authors of the papers published in the special issue are experts, as inferred from their history of publications from Scopus. 


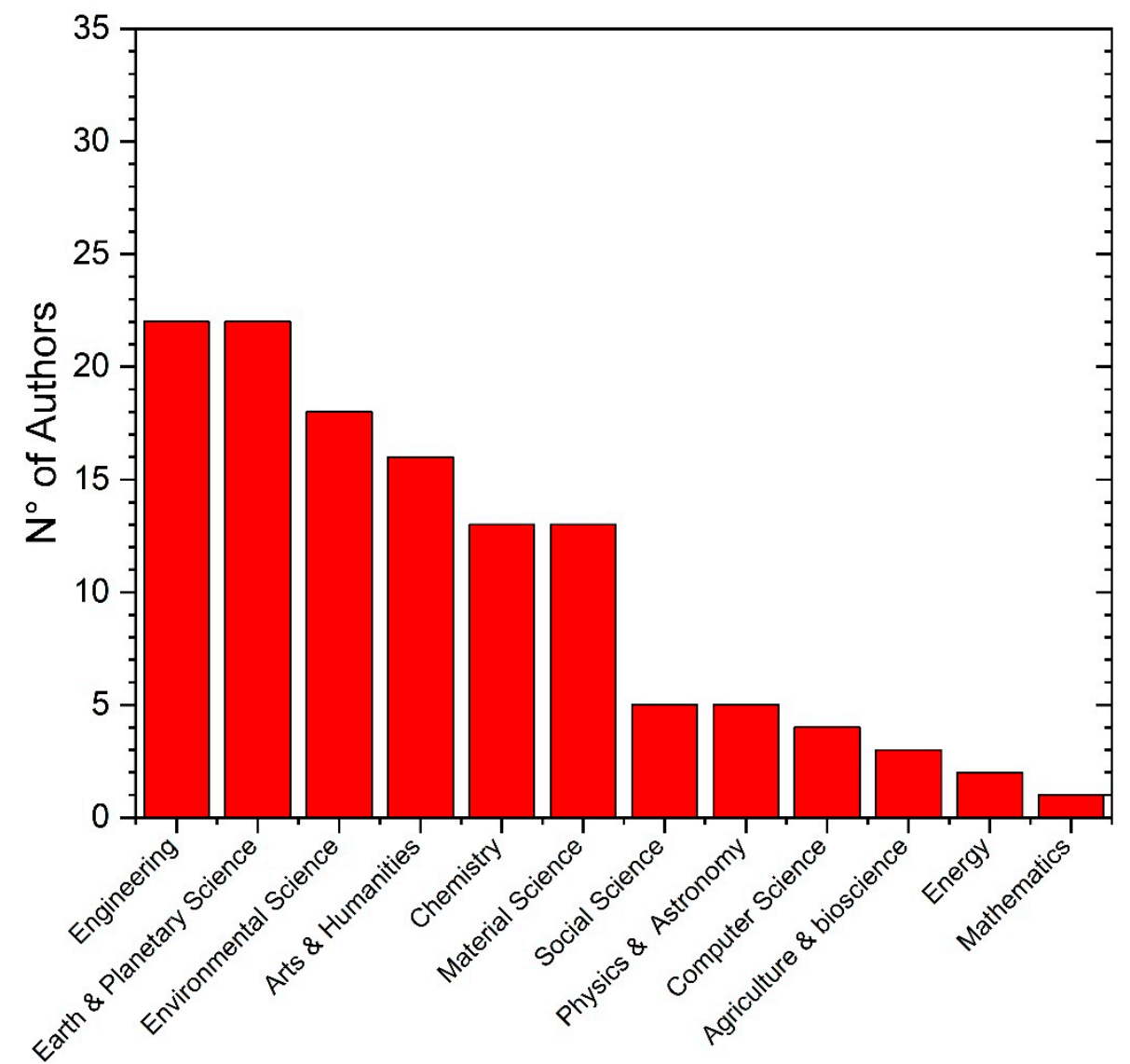

Figure 2. Expertise and scientific domain of authors publishing in this special issue, as inferred from their publications in Scopus.

Several situations can be observed generally:

(1) Within this SI, the common background among co-authors of the same paper and between authors of different works is on engineering, earth and planetary science, and environmental science. This make it clear the types of qualifications needed to understand the climate change at present and in the future.

(2) In each research team that has published a paper in this SI is present at least one or more experts on arts and humanities, chemistry, and material science, which are fields related to know-how in preventive conservation, the museum environment, and heritage and conservation science

(3) Authors with different professions have joined efforts to combine skills for building and climate simulation processing (e.g., physics and astronomy, as well as computer science, but again engineering and earth and planetary science) with arts and humanities or social science expertise.

Finally, using the data source for Scival metrics in the Scopus database, and specifically the Scival topic prominence, it is possible to know the topics in high-momentum areas. Prominence is in fact an indicator that shows current momentum by weighing three metrics for papers clustered in a topic: citation count, Scopus views, and average CiteScore. The topics treated within this SI (e.g., museums-buildings-preventive conservation; adaptation-climate change-vulnerability assessment) have an extremely high percentile prominence ranging from the 80 to 99.5 percentile, which is indicative as the authors are currently active in globally prominent topics. Figure 3 reports the visual result of the topic aggregation levels of this SI. It shows that the main core of expertise of the authors is on physics and astronomy (PHYS), chemistry (CHEM), chemical engineering (CENG), and materials science (MATE). 


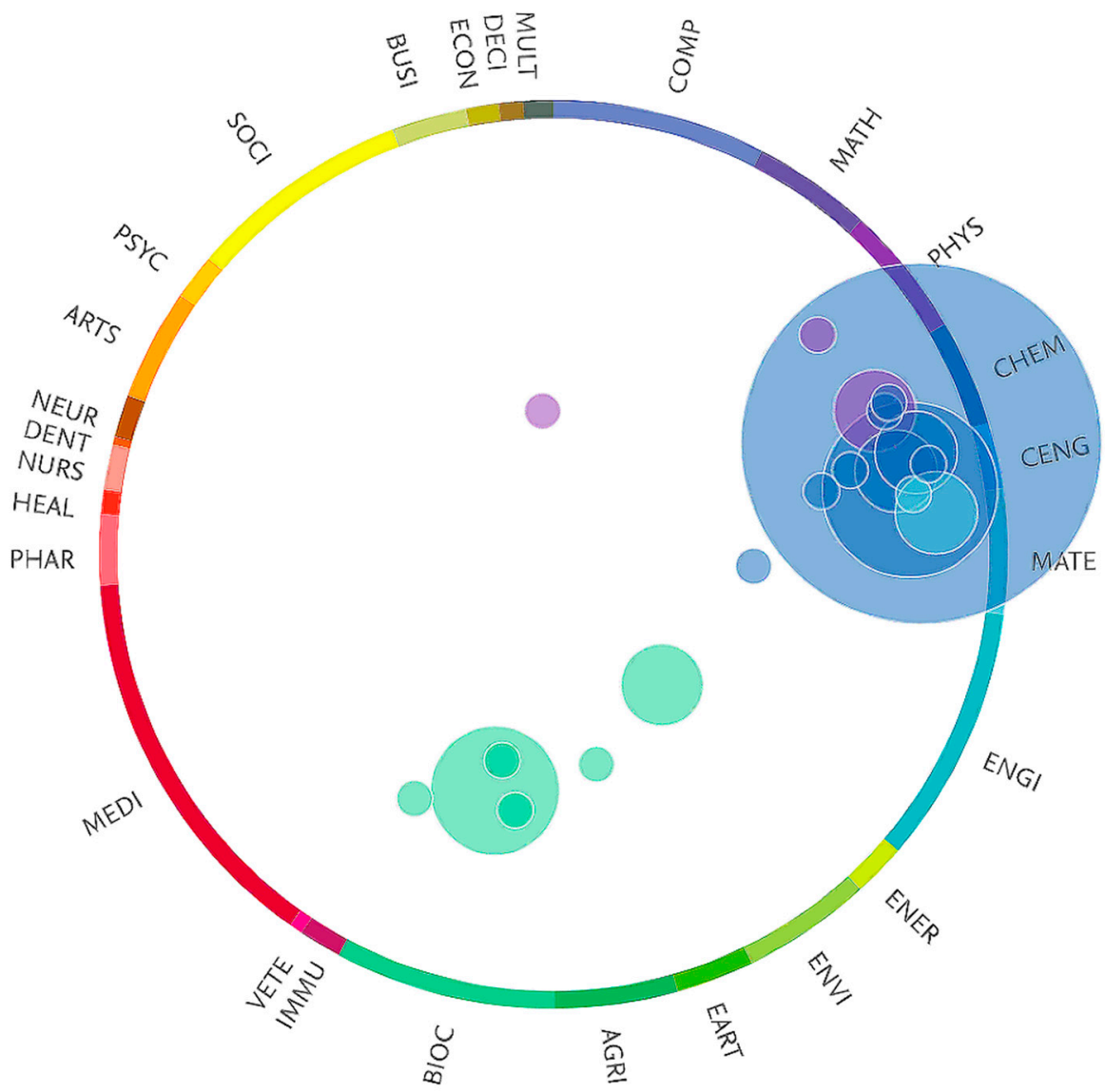

Figure 3. Visual representation of topics treated within this SI, as calculated by Scival prominence metrics in Scopus.

These skills are well interconnected. In addition, other areas of expertise at the boundary between biochemistry (BIOC) and biological sciences (AGRI), from the macro to micro scale, are growing and becoming linked together. Other skills, though, are new in the application to the conservation science field. This is the case of applied engineering (ENGI), which nowadays is a highly requested skill for numerical modelling for building or material component simulation (MATE), for the purpose of analyzing and testing new solutions in health monitoring or conservative interventions, as in the case of energy retrofitting solutions (ENER) in historical buildings. Other skills, with the potential to be applied in conservation science, are at an early stage of development or are less requested, as the case of pure climate simulations (EART) to estimate the impact of climate change outdoors/indoors, or mathematical models to assess the economic and social impact expected by climate change. This last topic, representative of adaptation to climate change and vulnerability assessment, is one that-at present-has both the highest prominence percentile (i.e., 99.5) and an increasing rate of interest. This means that the topics at the boundary between computer science/mathematics (COMP-MATH), economic/ econometrics (ECON), and decision science (DECI) are new and very promising topics that are likely to be well-funded in future calls for research grants.

\section{Key Messages for Future Research}

The wide portfolio of methodologies, data, and case studies presented in the contributions published in this special issue prove that heritage, material, and environmental science are currently vibrant research and practice domains, with expertise spread across the globe and teams fully exploiting the capability of innovative monitoring as well as experimental and numerical simulation techniques to investigate decay mechanisms on heritage materials and components, mainly on sites in different geographic and environmental contexts. It is clear that the intuition of heritage scientists, conservators, 
or experts in the field affects the assessment of climate change impacts on heritage materials, with respect to the analysis which a standardized evaluator could conduct. Experience sometime compensates for the difficulty encountered in estimating the exact decay rate, or in enlarging decay analysis to an extended family of materials and objects geometries still not considered in literature. Difficulties arise due to issues in quantitatively estimating natural ageing on materials, conservation-restoration treatments, or synergistic effects. These still unknown decay mechanisms, exacerbated nowadays by climate change, can be better understood through the collection of enough statistical data to be compared with experimental research and numerical simulations conducted on similar heritage materials and decay process to produce mathematical equations (i.e., damage functions). Specifically, long-term monitoring on standard environmental parameters, such as $\mathrm{T}, \mathrm{RH}$, and precipitation, as well as on data related to pollution, salt presence, and previous conservative treatments are the key to progress within the research.

What has also been reported in this SI is the interrupted flow of information between the theoretical knowledge available at the international level and the passing of that knowledge down to the local management scale. The lack of knowledge of management methodologies incorporating climate change impacts, as well as the need to identify and disseminate practical solutions and tools for mitigation, are tangible. To help heritage institutions adapt to a changing climate, or be effective in mitigation actions, less energy-intensive preventive conservation policies, evolving standards and guidelines over time, and a green-thinking approach to conservation should be implemented-for example, with the help of regulations and financial incentives. Finally, as support from the wider community is important for raising awareness and successful adapting to climate change, policies and initiatives to increase community engagement have to be realized.

Funding: This research received no external funding.

Acknowledgments: The guest editor would like to acknowledge all the authors for contributing to the special issue, as well as the anonymous peer reviewers for assessing the submitted manuscripts and greatly helping the authors enhance the scientific quality of their papers. Sincere gratitude goes to the Editorial Board and Office of Geosciences, especially to the managing editor Richard Li, for the invaluable help and assistance provided at all stages of the design, management, and publication of this special issue.

Conflicts of Interest: The authors declare no conflict of interest.

\section{References}

1. ICOMOS. International Charters for Conservation and Restoration; Monuments \& Sites, ICOMOS: München, Germany, 2004; Volume I, ISBN 3-87490-676-0.

2. Council of Europe. Recommendation of the Committee of Ministers to member States on the European Cultural Heritage Strategy for the 21st Century. In Proceedings of the 1278th meeting of the Ministers' Deputies, Strasbourg, France, 22 February 2017; Available online: https://rm.coe.int/16806f6a03 (accessed on 29 May 2019).

3. Sabbioni, C.; Brimblecombe, P.; Cassar, M. The Atlas of Climate Change Impact on European Cultural Heritage. ScieNtific Analysis and Management Strategies; Anthem Press: London, UK, 2010.

4. Leissner, J.; Kilian, R.; Kotova, L.; Jacob, D.; Mikolajewicz, U.; Broström, T.; Ashley-Smith, J.; Schellen, H.; Martens, M.; van Schijndel, J.; et al. Climate for Culture: Assessing the impact of climate change on the future indoor climate in historic buildings using simulations. Herit. Sci. 2015, 3, 38-52. [CrossRef]

5. Anaf, W.; Leyva Pernia, D.; Schalm, O. Standardized Indoor Air Quality Assessments as a Tool to Prepare Heritage Guardians for Changing Preservation Conditions due to Climate Change. Geosciences 2018, 8, 276. [CrossRef]

6. Carroll, P.; Aarrevaara, E. Review of Potential Risk Factors of Cultural Heritage Sites and Initial Modelling for Adaptation to Climate Change. Geosciences 2018, 8, 322. [CrossRef]

7. Haugen, A.; Bertolin, C.; Leijonhufvud, G.; Olstad, T.; Broström, T.A. Methodology for Long-Term Monitoring of Climate Change Impacts on Historic Buildings. Geosciences 2018, 8, 370. [CrossRef]

8. Loli, A.; Bertolin, C. Indoor Multi-Risk Scenarios of Climate Change Effects on Building Materials in Scandinavian Countries. Geosciences 2018, 8, 347. [CrossRef] 
9. Bylund Melin, C.; Hagentoft, C.; Holl, K.; Nik, V.; Kilian, R. Simulations of Moisture Gradients in Wood Subjected to Changes in Relative Humidity and Temperature Due to Climate Change. Geosciences 2018, 8, 378. [CrossRef]

10. Ciantelli, C.; Palazzi, E.; Von Hardenberg, J.; Vaccaro, C.; Tittarelli, F.; Bonazza, A. How Can Climate Change Affect the UNESCO Cultural Heritage Sites in Panama? Geosciences 2018, 8, 296. [CrossRef]

11. Fermo, P.; Goidanich, S.; Comite, V.; Toniolo, L.; Gulotta, D. Study and Characterization of Environmental Deposition on Marble and Surrogate Substrates at a Monumental Heritage Site. Geosciences 2018, 8, 349. [CrossRef]

12. Menéndez, B. Estimators of the Impact of Climate Change in Salt Weathering of Cultural Heritage. Geosciences 2018, 8, 401. [CrossRef]

13. Dotsika, E.; Kyropoulou, D.; Christaras, V.; Diamantopoulos, G. $\delta 13 C$ and $\delta 18 \mathrm{O}$ Stable Isotope Analysis Applied to Detect Technological Variations and Weathering Processes of Ancient Lime and Hydraulic Mortars. Geosciences 2018, 8, 339. [CrossRef]

14. Sesana, E.; Gagnon, A.; Bertolin, C.; Hughes, J. Adapting Cultural Heritage to Climate Change Risks: Perspectives of Cultural Heritage Experts in Europe. Geosciences 2018, 8, 305. [CrossRef]

(C) 2019 by the author. Licensee MDPI, Basel, Switzerland. This article is an open access article distributed under the terms and conditions of the Creative Commons Attribution (CC BY) license (http://creativecommons.org/licenses/by/4.0/). 